\title{
FEDSM-ICNMM2010-प००००
}

\section{ADVANCED INSTRUMENTATION FOR MEASURING FLUID-STRUCTURE COUPLING PHENOMENA IN THE GUIDE VANES CASCADE OF A PUMP-TURBINE SCALE MODEL}

\author{
Steven Roth* \\ Laboratory for Hydraulic Machines \\ Ecole Polytechnique Fédérale de Lausanne \\ 1007 Lausanne, Switzerland \\ Email: steven.roth@epfl.ch
}

\author{
Vlad Hasmatuchi \\ Francisco Botero \\ Mohamed Farhat \\ Francois Avellan \\ Laboratory for Hydraulic Machines \\ Ecole Polytechnique Fédérale de Lausanne \\ 1007 Lausanne, Switzerland
}

\begin{abstract}
In the present study, the fluid-structure coupling is investigated in the guide vanes cascade of a pump-turbine scale model placed in the EPFL PF3 test rig. The paper focuses on the advanced instrumentation used to get reliable and complete fluid-structure coupling results. Semi-conductor strain gages are installed on three guide vanes which are especially weakened to account for stronger fluid-structure coupling phenomena. These are statically calibrated in terms of torsion torque and bending force. A laser vibrometer is used to measure the vibrating guide vane velocity. Piezo-resistive pressure sensors are placed around the weakened guide vanes to monitor the influence of the structural vibrations on the surrounding flow. An underwater non-intrusive system is used to get an impulse excitation. The instrument set enables a reliable fluid-structure coupling investigation in hydraulic pump-turbine scale model. Finally, the results show a strong coupling between the vibrating guide vanes and the surrounding unsteady flow.
\end{abstract}

\footnotetext{
*Address all correspondence to this author.
}

\section{NOMENCLATURE}

A Slope of the pressure sensor linear regression $[\mathrm{Pa} / \mathrm{V}]$

a Regression coefficients vector for calibration matrix bending force components $[N / V]$

$B \quad$ Y-axis intercept of the pressure sensors linear regression $[\mathrm{Pa}]$

$b \quad$ Regression coefficients vector for calibration matrix torsion torque components $[\mathrm{Nm} / \mathrm{V}]$

$\tilde{C}_{p} \quad$ Pressure coefficient $[-]$

E Young modulus $[\mathrm{Pa}]$

$E \quad$ Pump-turbine specific energy $[\mathrm{J} / \mathrm{kg}]$

$F \quad$ Bending force $[N]$

$F^{\prime} \quad$ Relative fluctuating bending force $[-]$

$\bar{F} \quad$ Bending force time average $[N]$

$f \quad$ frequency $[\mathrm{Hz}]$

$f_{B, \text { air }}$ Guide vane bending eigen mode frequency in air $[\mathrm{Hz}]$

$f_{B, i} \quad$ Guide vane $i^{\text {th }}$ bending coupled eigen mode frequency in still water $[\mathrm{Hz}]$

$f_{p} \quad$ Impeller blade passage frequency $[\mathrm{Hz}]$

$f_{T, \text { air }}$ Guide vane torsion eigen mode frequency in air $[\mathrm{Hz}]$

$f_{T, i} \quad$ Guide vane $i^{\text {th }}$ torsion coupled eigen mode frequency in still water $[\mathrm{Hz}]$

$I_{i} \quad 2^{\text {nd }}$ moment of the $i^{\text {th }}$ section area $\left[m^{4}\right]$

$L \quad$ Total length of the partitioned guide vane $[m]$ 


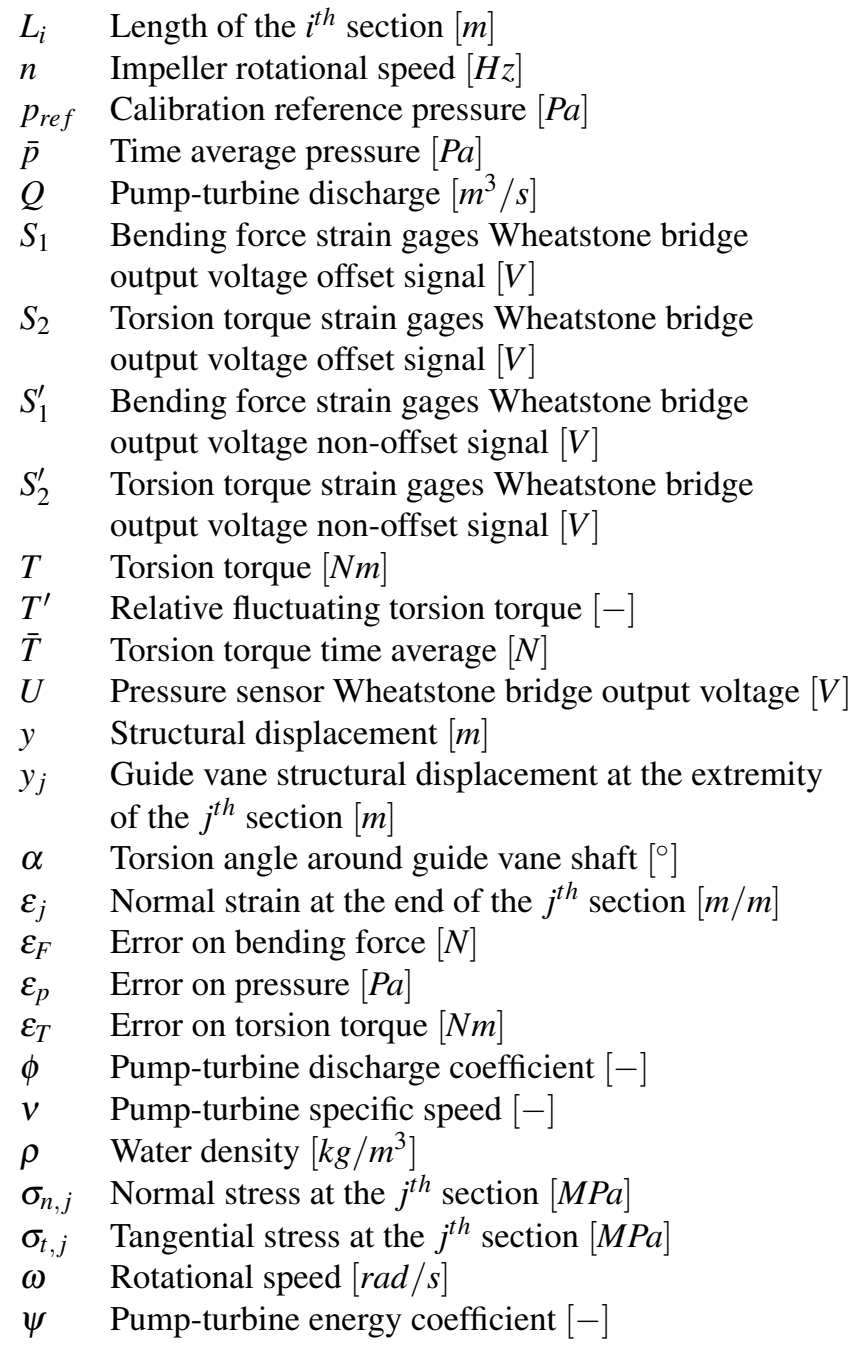

\section{INTRODUCTION}

Fluid-structure coupling in pump-turbine guide vanes cascade becomes increasingly relevant with the use of a new distributor type having an independent servomotor controlling each guide vane separately [1]. Each of the servomotors is characterized by its own transfer function which should consider neighboring vibrating blades in order to be efficient and safe. Furthermore, in the particular case of the emergency situation occurring when a guide vane safety shear pin breaks, the fluttering guide vane may change the overall dynamic of the guide vanes cascade. The understanding of the fluid-structure coupling in the guide vanes cascade is thus a great challenge which must be taken up to enable to deal with more reliable hydraulic pump-turbines in the future.

Fluid-structure coupling of blades cascade has widely been investigated in the case of axial gas turbomachines, the blade shape making them subject to a stronger fluid-structure coupling. [2] investigated both experimentally and numerically the case of a mistuned bladed-disk by exerting small perturbations on the blades stiffness. [3] dealt with mistuned bladed-disk with blades undergoing asymmetric aerodynamic forces. In the particular case of gas turbomachines, the coupling between blades is accounted for in the so-called influence coefficient matrix modeled as a stiffness matrix with non-diagonal terms. In the case of hydraulic machines, inertial coupling must be accounted for because of the greater fluid density. The corresponding concept of added mass has been tackled mainly for bluff bodies [4]. Energy dissipation has been studied on a variety of bluff bodies such as cylinders [5]. Magnetic excitation has been used to verify experimentally [6] the linear dependence of the damping coefficient with the flow velocity obtained analytically with potential flow theory [7].

The present paper starts with the definition of the case study - pump-turbine scale model, individual guide vane and guide vanes cascade - before tackling the experimental setup in detail. The focus is mainly on the guide vanes design which are especially weakened to account for stronger fluid-structure coupling. Impulse and forced response are carried out and the corresponding results are given. Finally, the instrument set ability to deal with fluid-structure coupling phenomena is brought to light in a short concluding discussion.

\section{CASE STUDY}

The case study consists of a guide vanes cascade of a $v=$ 0.19 specific speed pump-turbine scale model, $v$ being defined in (1).

$$
v=\frac{\omega(Q / \pi)^{0.5}}{(2 E)^{0.75}}
$$

where $\omega$ represents the rotational speed, Q the discharge and $\mathrm{E}$ the runner specific energy. The impeller features 9 blades and 20 guide vanes. The wicket gate opening angle is set to $18^{\circ}$. The guide vane material is bronze $\operatorname{CuSn} 12(E=90-110 \mathrm{GPa}$, $\left.\sigma=140 \mathrm{MPa}, \rho=8600 \mathrm{~kg} / \mathrm{m}^{3}\right)$. The focus is on three adjacent guide vanes $(\mathrm{B}, \mathrm{C} \& \mathrm{D})$ which have been voluntary weakened in order to account for stronger fluid-structure coupling phenomena (see FIGURE 1).

The other guide vanes are much stiffer meaning that they vibrate with a lower amplitude and that their eigen frequencies are much higher than those of the weakened blades. In this way, the three guide vanes are able to be decoupled from the overall cascade. The weakening of the three adjacent guide vanes is made at the level of their shaft. The hydraulic profile is therefore similar 


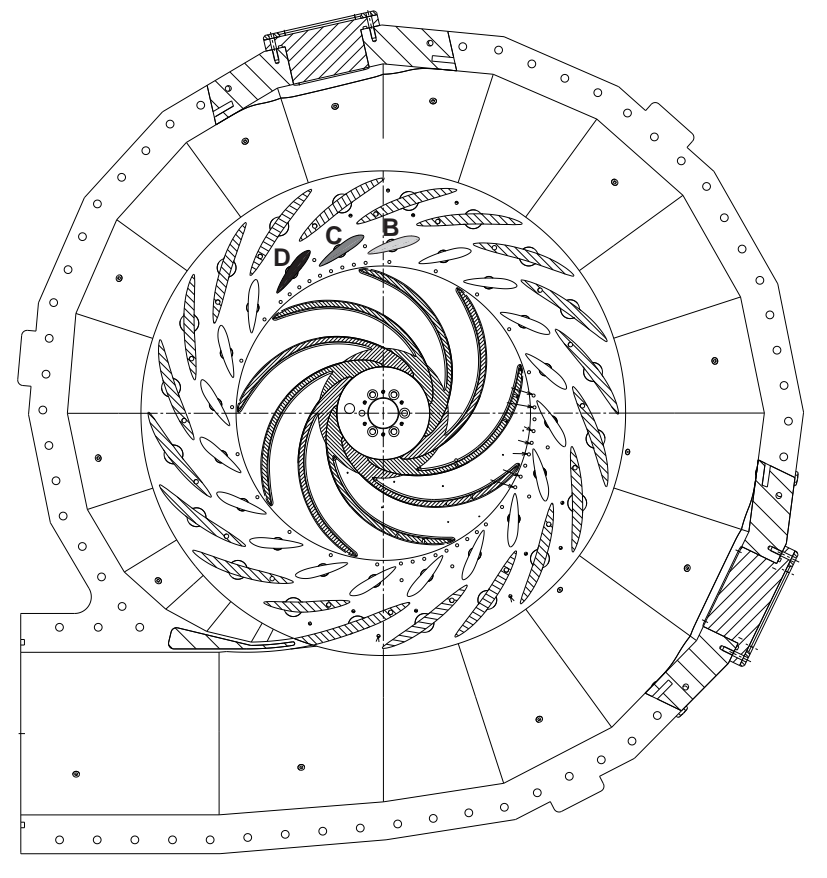

FIGURE 1. PUMP-TURBINE WITH THE WEAKENED GUIDE VANES

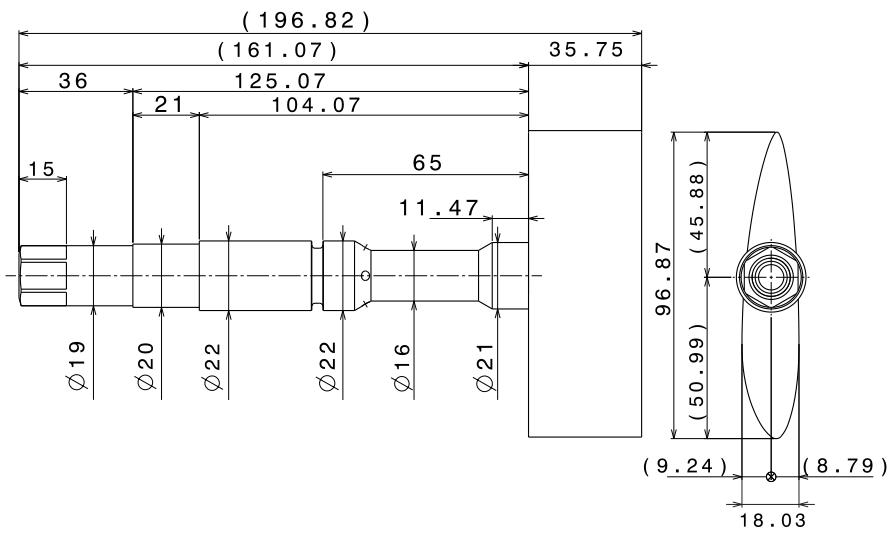

FIGURE 2. WEAKENED GUIDE VANE [mm]

for all the guide vanes constituting the blade cascade. The dimensions of the final design of the weakened guide vanes is shown in FIGURE 2. These guide vanes are clamped with a stiff flange on the shaft at the level of the diameter $\varnothing 19 \mathrm{~mm}$. The design of the weakened guide vanes is explained in the following section since it is directly related with the measurement requirements of the strain gages.

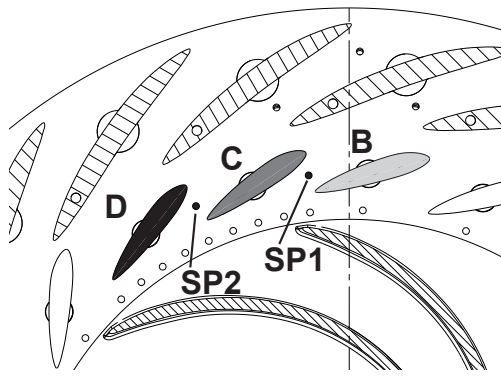

FIGURE 3. SPARK PLUG LOCATIONS SP1 AND SP2

\section{EXPERIMENTAL SETUP}

The pump-turbine model is placed in the EPFL PF3 test rig featuring $100 \mathrm{~m}$ maximum head, $1.4 \mathrm{~m}^{3} / \mathrm{s}$ and $1500 \mathrm{rpm}$. Advanced instrument set is installed in order to monitor the fluidstructure coupling in the most complete and reliable manner. First, two impulse excitation systems are used to get the impulse response of the guide vanes in air and in water. Second, the weakened guide vanes are equipped with semi-conductor strain gages in order to monitor both relative fluctuating bending and torsion. A laser vibrometer is also used to get the vibration velocity of the guide vane C. Finally, pressure sensors are installed mainly around the weakened guide vanes to monitor the response of the unsteady flow to the guide vanes vibration.

\section{In-air impulse excitation system}

For modal analysis in air, an instrumented hammer Dytran $5850 \mathrm{~B}$ is used. It has both the role of exciting structures as well as triggering the measurement. The guide vanes are hit at the level of their leading edge in order to excite both bending and torsion modes.

\section{In-water impulse excitation system}

A non-intrusive system is used to create an impulse excitation in water (see [10] and [11]). A spark plug is flush mounted in the bottom flange between two guide vanes. Two locations are possible: SP1 between guide vanes B and C, SP2 between guide vanes $\mathrm{C}$ and D (see FIGURE 3). The discharge of $1550 \mathrm{nF}$ capacitor in a very short time $(<25 \mu \mathrm{s})$ generates a spark producing a rapid increase of the water temperature. Strong shock waves are generated with the explosive growing of a vapor bubble and travel towards the blade. An impulse excitation is so provided. Several collapses and rebounds of the bubble occur, but the first shock waves is the strongest and provides the most relevant exciting pressure impulse. The pressure excitation of very short duration, due to the traveling speed of the shock waves (speed of sound in water: $1485 \mathrm{~m} / \mathrm{s}$ ), address a wide band frequency range.

The visualization of the spark generated bubble is obtained with an ultra high speed PHOTRON FASTCAM SA1.1 video 


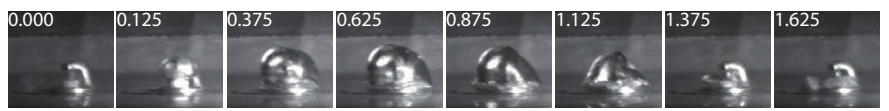

FIGURE 4. SPARK GENERATED BUBBLE VISUALIZATION AT ZERO FLOW VELOCITY (TIME IN [ms])

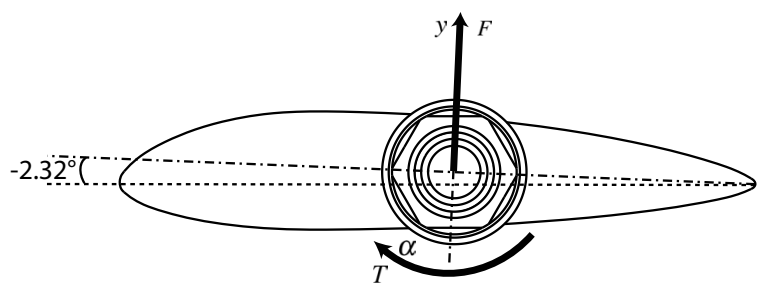

FIGURE 5. TORSION TORQUE AND BENDING FORCE DIRECTION

system at 8'000 frames per second with a resolution of $832 \times 608$ pixels. The growing and then collapsing vapor bubble can be observed in FIGURE 4.

\section{Relative fluctuating torsion and bending measure- ments}

Three guide vanes are equipped with semi-conductor strain gages. On each guide vane, two full Wheatstone bridges are installed to monitor both the torsion and the bending. The torsion torque and bending force location and direction are shown in FIGURE 5. The torsion torque is situated around the guide vane shaft. Positive torque is defined as the torque providing positive incidence angle. The bending force application point is located at the center of the spanwidth on the prolongation of the shaft axis. The direction of this force is perpendicular to the line inclined with an angle of $-2.32^{\circ}$ from the hydrofoil's cord. Positive bending force is defined as the force inducing positive incidence angle.

Guide vane design. The guide vane design is closely related to the requirements and limitations of strain measurement. They are listed and developed below.

1. Enable the monitoring of guide vane bending and torsion

2. Respect dimensional constraints

3. Do not exceed material elastic limit

4. Do not exceed strain gage maximum allowable strain
TABLE 1. STRAIN GAGES CHARACTERISTICS

\begin{tabular}{cc}
\hline Characteristic & Value \\
\hline Gage length & $2 \mathrm{~mm}$ \\
Gage resistance & $120 \Omega$ \\
Gage factor & 100 \\
Max. allowable strain & $3000 \mu \mathrm{m} / \mathrm{m}$ \\
Max. allowable current & $20 \mathrm{~mA}$ \\
\hline
\end{tabular}

The main requirement is to enable the monitoring of guide vanes bending and torsion with rotor-stator interaction (RSI) excitation. For that purpose, numerical results of unsteady torsion torque and bending force acting on the guide vanes are extracted from numerical flow simulations of the entire pump-turbine model [8]. The maximal torque and force are used in static analytical and numerical computations of the structure. From a more practical point of view, the strain gages must be accessible by their wires through the shaft - shaft bore is therefore essential. Furthermore, the strain gages thickness once glued on the shaft should not be in contact with the surface of the external bore. The shaft should also not be in contact with the external bore at the level of the section 2. These points impose geometrical constraints. The minimum allowable internal shaft diameter is $8 \mathrm{~mm}$ and the maximum allowable external diameter of the shaft sensitive weakened part is $16 \mathrm{~mm}$. The maximum allowable displacement at the section 2 is $1 \mathrm{~mm}$. The third requirement is the material elastic limit to ensure the guide vane not to be damaged when operating the machine where strong rotor-stator interaction is observed. Finally, the gage maximal allowable strain $(3000 \mu \mathrm{m} / \mathrm{m})$ recommended by the manufacturer should not be exceeded.

Semi-conductor strain gages (type: Kyowa KSN-2-120-F311) are chosen because of their high sensitivity suitable for dynamic measurements. Furthermore, these particular strain gages are compact and able to be glued on a surface with curvature radius down to $8 \mathrm{~mm}$. The strain gages main characteristics are listed in TABLE 1 .

A guide vane analytical model is used to facilitate the design optimization. The guide vane is considered as a beam and partitioned in 9 sections, each being treated separately (see FIGURE 7). The bending and torsion are decoupled in such a way that two models are developed separately. The simple bending model is based on the assumption that the bending moment has one single component perpendicular to the bending plane. According to [9], the deformation $y_{j}$ at the extremity of the $j^{\text {th }}$ section due to a local force $\mathrm{F}$ applied on the point mentioned above (middle of the 


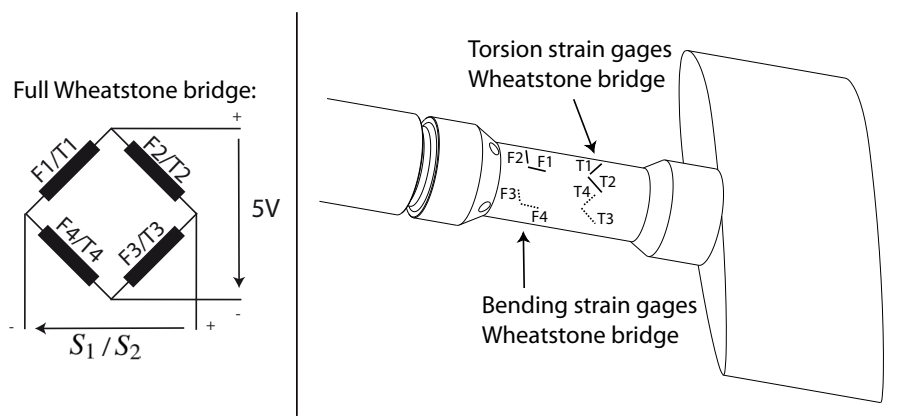

FIGURE 6. STRAIN GAGES BRIDGES

span width and on the prolongation of the shaft axis) writes:

$$
\begin{aligned}
y_{j}=\sum_{i=j}^{9}\left(\frac{F L_{i}^{3}}{3 E I_{i}}\right)+\sum_{i=j+1}^{9}\left(L_{i-1} \cdot \sin ^{-1}\left(\frac{F L_{i}^{2}}{2 E I_{i}}\right)\right) \\
+\sum_{i=j, j>1}^{9}\left(\frac{F\left(L-\sum_{k=1}^{i} L_{k}\right) L_{i}^{2}}{3 E I_{i}}\right) \\
+\sum_{i=j+1, j>1}^{9}\left(L_{i-1} \cdot \sin ^{-1}\left(\frac{F\left(L-\sum_{k=1}^{i} L_{k}\right) L_{i-1}}{E I_{i-1}}\right)\right)
\end{aligned}
$$

where $L_{i}$ is the length of the $i^{t h}$ section, $I_{i}$ the transverse $2^{\text {nd }}$ moment of the $i^{\text {th }}$ section area, E the Young modulus, $L$ the total length of all the sections. The trigonometric functions in equation (2) express the deflection due to the rotation of each section tip.

For bending case, the tangential stress is rightfully neglected compared with normal stress. The normal stress $\sigma_{j}$ at the $j^{t h}$ section writes:

$$
\sigma_{n, j, j>1}=\frac{y_{j} F\left(L-\sum_{k=1}^{j} L_{k}\right)}{I_{j}}
$$

The simple torsion model used leads to the expression (4) for the torsion angle $\alpha_{j}$ at the end of the $j^{t h}$ section.

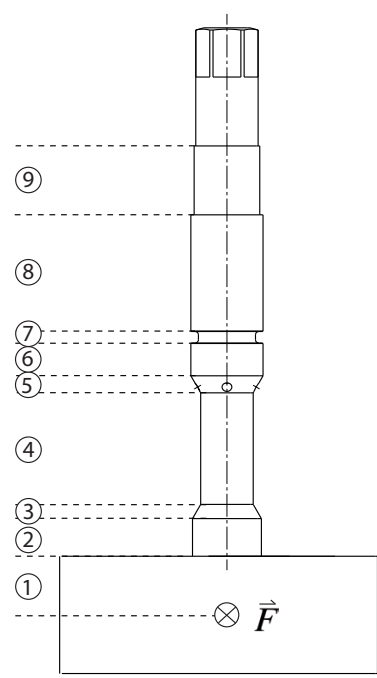

FIGURE 7. GUIDE VANE PARTITIONING

$$
\alpha_{j}=\sum_{i=j}^{9}\left(\frac{2 M L_{i}(1+v)}{E I_{p, i}}\right)
$$

where $M$ is the torsion torque, $v$ the Poisson's coefficient and $I_{p, i}$ the $2^{\text {nd }}$ polar moment of the $i^{\text {th }}$ section area.

Normal stress due to torsion is assumed to be zero and the tangential stress is given by equation (5).

$$
\sigma_{t, j}=\frac{D_{j} M}{I_{p, j}}
$$

where $D_{j}$ is the external diameter of the $j^{\text {th }}$ section.

Three parameters are varied in the design optimization: the sensitive part length $L_{4}$, the shaft internal diameter and the shaft external diameter.

The guide vane is numerically modeled in order to verify the theoretical model once the final design is obtained. Static simulations are performed with the finite element based ANSYS solver. The mesh is made with hexahedral 20-nodes finite elements (see FIGURE 8) and has a total of 67567 nodes. Zero DOF's is applied at the clamping location. Torsion torque and bending force are applied on the hydrofoil. The sparse direct method Block Lanczos is used to get the results.

The TABLE 2 compares the results obtained with both analytical approach and numerical simulations at the weakened section. The numerical simulation is then used to verify the 


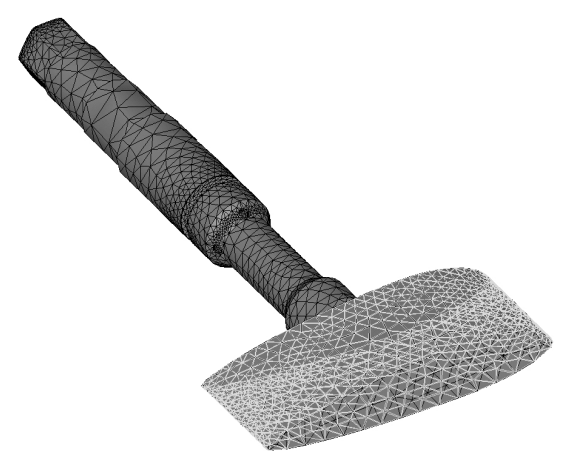

FIGURE 8. GUIDE VANE FINITE ELEMENTS MESH

TABLE 2. NUMERICAL AND THEORETICAL MODEL COMPARISON

\begin{tabular}{cccc}
\hline Requirements & $\begin{array}{c}\text { Analytical } \\
\text { approach }\end{array}$ & $\begin{array}{c}\text { Numerical } \\
\text { simulation }\end{array}$ & $\begin{array}{c}\text { Relative } \\
\text { difference }\end{array}$ \\
\hline$\sigma_{n, 4, \max }$ & $22.7 \mathrm{MPa}$ & $21.5 \mathrm{MPa}$ & $5 \%$ \\
$\sigma_{t, 4, \max }$ & $26.5 \mu \mathrm{m} / \mathrm{m}$ & $27.0 \mu \mathrm{m} / \mathrm{m}$ & $2 \%$ \\
\hline
\end{tabular}

design requirements when the bending and torsion is applied at the same time. The maximum Von Mises stress is $60 \mathrm{MPa}$ which is much less than the material elastic limit $\left(\sigma_{e}=140 \mathrm{MPa}\right)$ and the maximum principal strain takes the maximum value of $500 \mu \mathrm{m} / \mathrm{m}$ which is much less than the allowable strain for the strain gages $(3000 \mu \mathrm{m} / \mathrm{m})$. The displacement at the end of the section 2, being $0.3 \mathrm{~mm}$ stays below the displacement allowed by the external bore gap $(1 \mathrm{~mm}$.

Calibration. The guide vanes are calibrated statically in terms of bending force and torsion torque. Thirty-nine pure bending forces and twenty-seven pure torsion torques ranging respectively from $-150 \mathrm{~N}$ to $150 \mathrm{~N}$ and from $-33 \mathrm{Nm}$ to $33 \mathrm{Nm}$ are applied on each of the guide vanes (see FIGURE 9). The calibration rig does not allow for combined force and torque. The calibration matrix $\mathrm{C}$ of a given guide vane is obtained using a multivariate linear regression separately for bending force and torsion torque. The relation linking the thirty-nine applied bending forces $F_{j}(1 \leq j \leq 39)$, which consist of the dependent variables, to the strain gages bridges measured offset signals $S_{1, j}$ and $S_{2, j}$, the regressors, is given by (6), the $a$ vector containing the regression coefficients and the $\varepsilon$ vector the residuals.
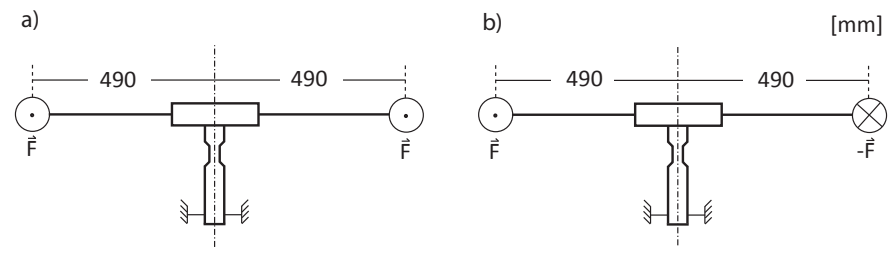

FIGURE 9. FORCE AND TORQUE CALIBRATION PRINCIPLE

$$
F=\left(\begin{array}{c}
F_{1} \\
F_{2} \\
\vdots \\
F_{39}
\end{array}\right)=S a+\varepsilon_{F}=\left(\begin{array}{cc}
S_{1,1} & S_{1,2} \\
S_{2,1} & S_{2,2} \\
\vdots & \vdots \\
S_{39,1} & S_{39,2}
\end{array}\right)\left(\begin{array}{l}
a_{1} \\
a_{2}
\end{array}\right)+\left(\begin{array}{c}
\varepsilon_{F, 1} \\
\varepsilon_{F, 2} \\
\vdots \\
\varepsilon_{F, 39}
\end{array}\right)
$$

In the same manner, the twenty-seven pure torsion torques are linked to the strain gage signals through the regression coefficients vector $b$ with the relation (7).

$$
T=\left(\begin{array}{c}
T_{1} \\
T_{2} \\
\vdots \\
T_{27}
\end{array}\right)=S b+\varepsilon_{T}=\left(\begin{array}{cc}
S_{1,1} & S_{1,2} \\
S_{2,1} & S_{2,2} \\
\vdots & \vdots \\
S_{27,1} & S_{27,2}
\end{array}\right)\left(\begin{array}{l}
b_{1} \\
b_{2}
\end{array}\right)+\left(\begin{array}{c}
\varepsilon_{T, 1} \\
\varepsilon_{T, 2} \\
\vdots \\
\varepsilon_{T, 27}
\end{array}\right)
$$

The calibration matrix $C$ consists finally of regrouping the regression coefficients of the two approximations. The bending force $F$ and torsion torque $T$ acting on the guide vanes are then related to the strain gages Wheatstone bridges signals $S_{1}$ and $S_{2}$ as follows.

$$
C S=\left(\begin{array}{ll}
a_{1} & a_{2} \\
b_{1} & b_{2}
\end{array}\right)\left(\begin{array}{l}
S_{1} \\
S_{2}
\end{array}\right)=\left(\begin{array}{l}
F \\
T
\end{array}\right)
$$

The bending force and torsion torque sensitivity to nonoffset signal $S_{1}^{\prime}$ and $S_{2}^{\prime}$ as well as the related residuals (circles), defined in equations (9) and (10), are given in FIGURES 10 to 13 for the guide vane $\mathrm{C}$. The crosses represent the measured points and the linear curve express the regression curve.

$$
\begin{aligned}
& \varepsilon_{F}=F-\left(a_{1} \cdot S_{1}+a_{2} \cdot S_{2}\right) \\
& \varepsilon_{T}=T-\left(b_{1} \cdot S_{1}+b_{2} \cdot S_{2}\right)
\end{aligned}
$$




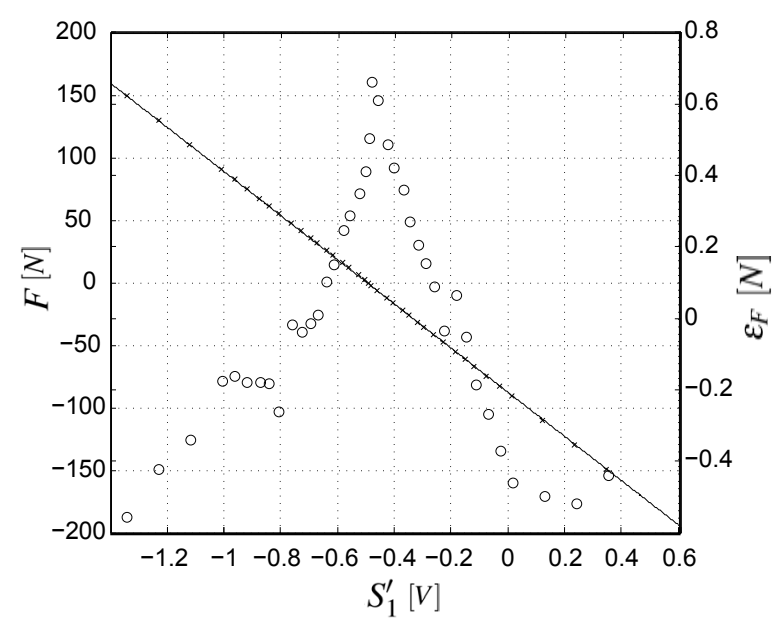

FIGURE 10. BENDING FORCE SENSITIVITY TO $S_{1}^{\prime}$ VOLTAGE AND RELATED RESIDUALS

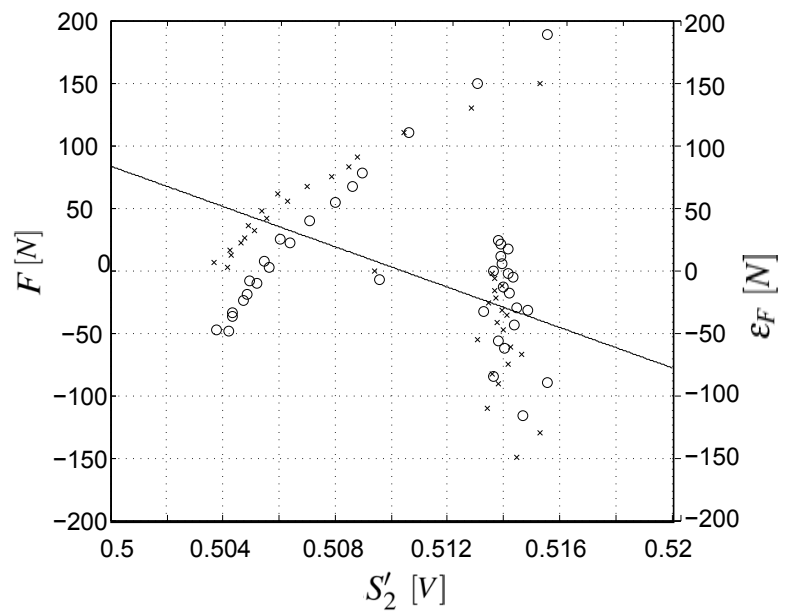

FIGURE 11. BENDING FORCE SENSITIVITY TO $S_{2}^{\prime}$ VOLTAGE AND RELATED RESIDUALS

Since the guide vanes are statically calibrated, care has to be taken when analyzing bending force and torsion torque signals in dynamic cases. Dynamically, the structural strain is amplified near resonance leading in an overestimation of the force and torque signal. To represent correctly the signals in dynamic cases, the relative fluctuating bending force $F^{\prime}$ and torsion torque $T^{\prime}$ are introduced and respectively given by equation (11) and (12).

$$
F^{\prime}=\frac{F-\bar{F}}{\bar{F}}
$$

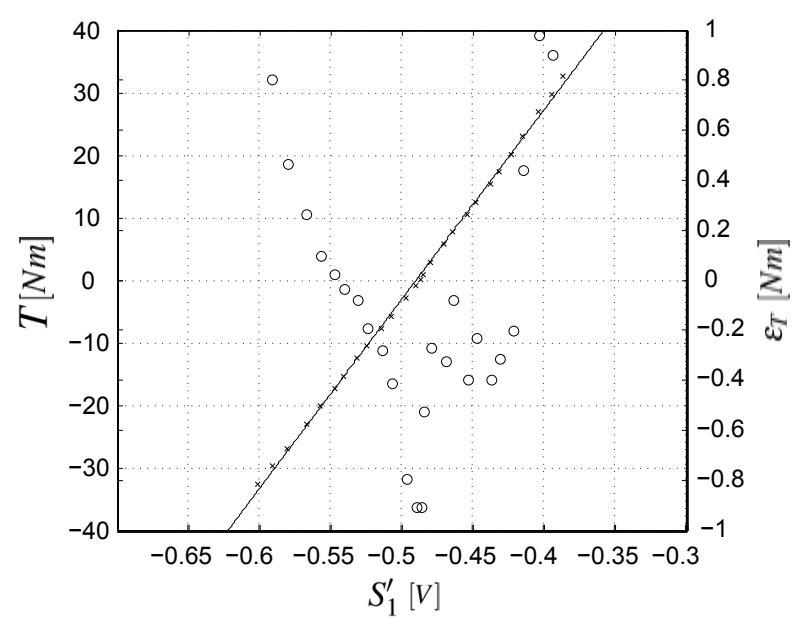

FIGURE 12. TORSION TORQUE SENSITIVITY TO $S_{1}^{\prime}$ VOLTAGE AND RELATED RESIDUALS

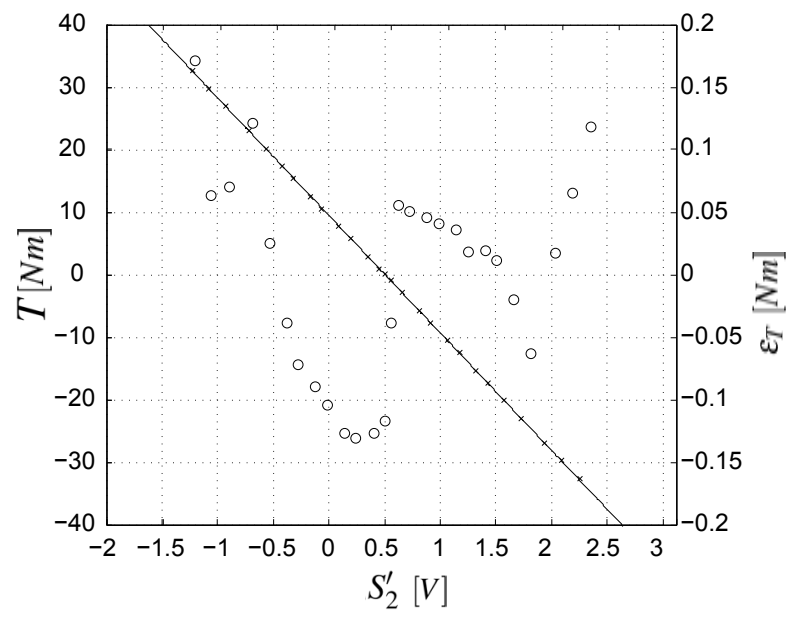

FIGURE 13. TORSION TORQUE SENSITIVITY TO $S_{2}^{\prime}$ VOLTAGE AND RELATED RESIDUALS

$$
T^{\prime}=\frac{T-\bar{T}}{\bar{T}}
$$

where $\bar{F}$ and $\bar{T}$ are respectively the bending force and torsion torque time average.

Because of the static calibration of the guide vanes, the relative fluctuating force is similar to the relative fluctuating displacement $y^{\prime}$ and the same is true for the relative fluctuating torque $T^{\prime}$ and rotation $\alpha^{\prime}$. Introducing the bending stiffness $K$, the equation (13) proves the equality for the case of bending 
TABLE 3. LASER-DOPPLER VIBROMETER CHARACTERISTICS

\begin{tabular}{cc}
\hline Characteristic & Value \\
\hline Bandwidth & $2 \mathrm{~mm}$ \\
Max. velocity & up to $500 \mathrm{~mm} / \mathrm{s}$ \\
Operating distance & $0.2-30 \mathrm{~m}$ \\
\hline
\end{tabular}

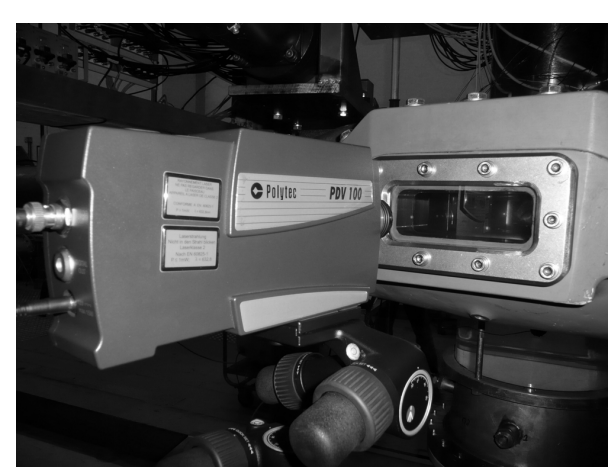

FIGURE 14. LASER-DOPPLER VIBROMETER POSITIONING

force. The same development can be made for torsion torque.

$$
F^{\prime}=\frac{F-\bar{F}}{\bar{F}}=\frac{K y-K \bar{y}}{K \bar{y}}=\frac{y-\bar{y}}{\bar{y}}=y^{\prime}
$$

\section{Vibrating guide vane $\mathbf{C}$ velocity measurement}

A laser-Doppler vibrometer is used to measure the vibrating guide vane $\mathrm{C}$ velocity in a non-intrusive way. This instrument consists of a laser source and uses an interferometer to measure the Doppler effect due to vibrations. The single point "out of plane" vibrations type of vibrometer is used, Polytec PDV-100. This particular vibrometer is portable and possesses integrated low- and high-pass filters. The main characteristics of the instrument are given in TABLE 3.

The optical access to the guide vane $C$ is ensured by two Plexiglas stay vanes and a Plexiglas window placed in the spiral casing (see FIGURES 14 and 15). The vibration velocity is integrated to get the displacement. A simple forward finite difference scheme is used. The high sampling frequency $(51.2 \mathrm{kHz})$ does not induce great difference between first and second order integration scheme.

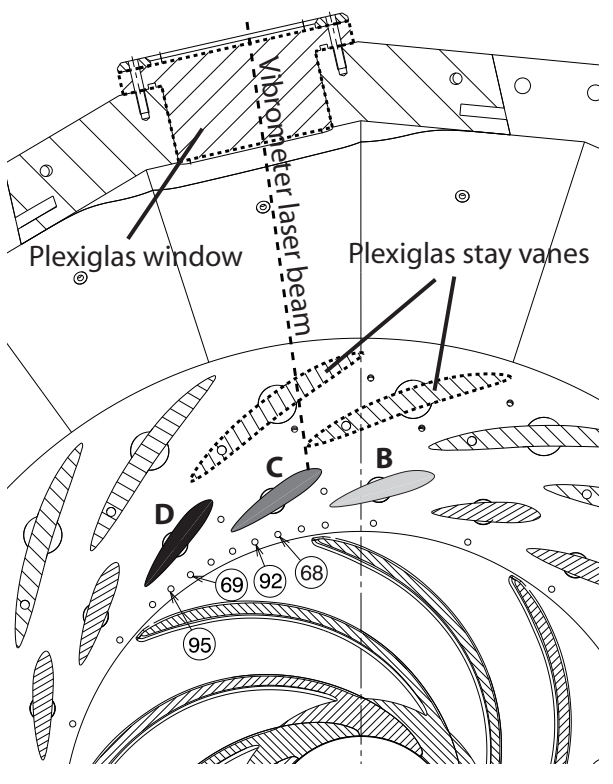

FIGURE 15. PRESSURE SENSORS LOCATIONS AND VIBROMETER LASER BEAM OPTICAL ACCESS

\section{Fluctuating pressure measurements}

Twenty-nine miniature piezo-resistive pressure sensors are installed in the pump-turbine stator mainly around the weakened guide vanes. They are flush mounted in the upper flange. Four of them are shown in FIGURE 15 since pressure signals at these points are used later on.

The aim is to monitor the fluctuating pressure simultaneously with the guide vanes fluctuating torsion and bending. Since the pressure sensors are not resistant to cavitation, care must be taken during the pump-turbine operation in order to prevent any cavitation onset in the concerned area. The pressure sensors are calibrated statically up to 6 bar absolute static pressure with 50 intermediate points. Ascending and descending orders are carried out to catch any hysteresis behavior which could be a sign of damaged sensors. High-accuracy reference pressure sensor HUBER is used. The FIGURE 16 shows the calibration curve $p_{r e f}(U)$ (obtained by linear regression in the least square sense) and the related residuals (circles), defined in equation ((14)), for a given pressure sensor. It reveals the high accuracy of the sensors and the precision of their calibration. The crosses represent the measured points.

$$
\varepsilon_{p}=p_{r e f}-(U \cdot A+B)
$$

where $A$ is the slope of the linear regression, $B$ the y-axis intercept on FIGURE 16, $U$ the output voltage of the pressure 


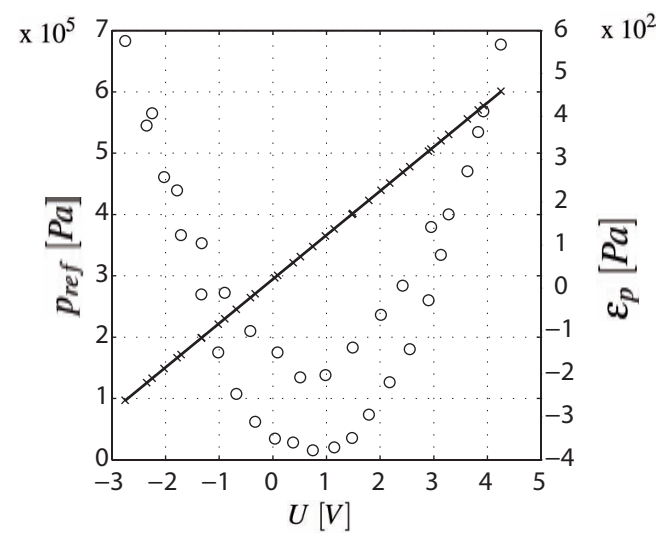

FIGURE 16. CALIBRATION OF ONE OF THE PRESSURE SENSORS

sensor and $p_{r e f}$ the reference pressure.

The pressure coefficient $\tilde{C}_{p}$ used later on is defined as given in equation (15).

$$
\tilde{C}_{p}=\frac{p-\bar{p}}{\rho \cdot E}
$$

where $p$ is the pressure, $\bar{p}$ the time average pressure, $\rho$ the water density and $E$ the specific energy of the pump-turbine related to the operating point.

\section{RESULTS}

\section{Impulse response}

In this section, the impulse response of the guide vanes both in air and in still water are analyzed. Vibrations signals are digitized at $51.2 \mathrm{kHz}$ sampling frequency over $0.32 \mathrm{~s}$ yielding a $3.125 \mathrm{~Hz}$ frequency resolution. 8 different acquisitions are made and the spectra presented later on are averaged over these samples. The air does not induce any coupling effect between the blades as it has been predicted, mainly due to low fluid density. The FIGURES 17 and 18 give respectively the spectra of the bending force impulse response and of the torsion torque impulse response for the three guide vanes $(\mathrm{gvB}, \mathrm{gvC}$ and gvD). The Fourier transform of the diverse responses is directly plotted since the time-history of the excitation is not known and therefore the response cannot be normalized as it should normally be.

A first observation can be made by comparing these two figures. On the one hand, the bending force strain gages bridges capture only the bending mode, meaning that these sensors are not very sensitive to torsion motion. On the other hand, the

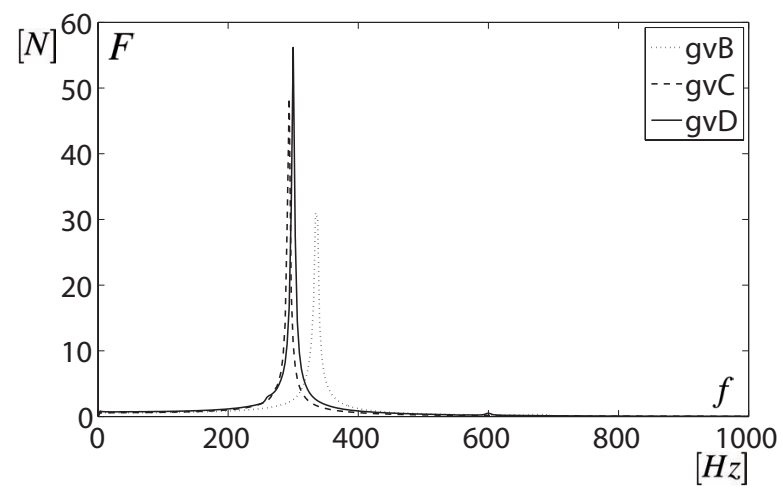

FIGURE 17. SPECTRA OF THE THREE GUIDE VANES (gvB, gvC and gvD) BENDING FORCE IMPULSE RESPONSE IN AIR

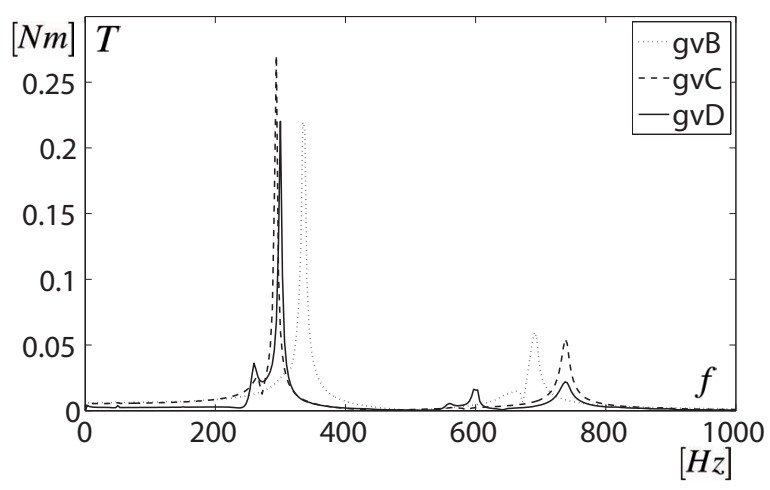

FIGURE 18. SPECTRA OF THE THREE GUIDE VANES (gvB, gvC and gvD) TORSION TORQUE IMPULSE RESPONSE IN AIR

torsion torque strain gages bridges are sensitive to both bending and torsion motion. The sensitivity of the torsion strain gages bridges to bending motion is due to the fact that each of the strain gages reacts in this case and any tiny misalignment of the strain gages constituting the bridge induces a signal. Although the impulse excitation provided by the instrumented hammer tends to excite both modes at the same level by hitting the blade at the leading edge, the bending mode seems nevertheless to be more excited than the torsion mode. This explains the higher amplitude for the bending mode in FIGURE 18. The impulse response in air shows a different dynamic behavior of the guide vane $\mathrm{B}$ compared with the two others. Its bending eigen frequency is higher whereas its torsion eigen frequency is lower (see TABLE 4). Since the geometrical dimensions of all the guide vanes are similar, the reason of this mistuning stands in slightly different material properties or in the way of mounting the guide vanes in the upper flange (bore diameter tolerance, gap value, etc.). 
TABLE 4. EIGEN FREQUENCIES IN AIR $[\mathrm{Hz}]$

\begin{tabular}{ccc}
\hline Guide vane & $\mathbf{f}_{\mathbf{B}, \mathbf{a i r}}$ & $\mathbf{f}_{\mathbf{T}, \mathbf{a i r}}$ \\
\hline B & 334 & 690 \\
C & 294 & 737 \\
D & 300 & 737 \\
\hline
\end{tabular}

TABLE 5. EIGEN FREQUENCIES IN STILL WATER [Hz]

\begin{tabular}{ccccccc}
\hline Guide vane & $\mathbf{f}_{\mathbf{B} \mathbf{1}}$ & $\mathbf{f}_{\mathbf{B} \mathbf{2}}$ & $\mathbf{f}_{\mathbf{B} \mathbf{3}}$ & $\mathbf{f}_{\mathbf{T} \mathbf{1}}$ & $\mathbf{f}_{\mathbf{T} \mathbf{2}}$ & $\mathbf{f}_{\mathbf{T} \mathbf{3}}$ \\
\hline B & 225 & 256 & 291 & 603 & - & - \\
C & 225 & 256 & - & 603 & 625 & 647 \\
D & 225 & 256 & - & 603 & 625 & 647 \\
\hline
\end{tabular}

In still water, the fluid couples each of the three guide vanes to each other (see FIGURES 19 to 22) mainly due to inertial effect. Three coupled bending eigen modes replace the three individual bending eigen modes for the case in air. The same happens for the torsion eigen modes (see TABLE 5). Depending on the spark plug location (SP1 \& SP2), each of the coupled mode is more or less excited. In the TABLE 5, it can be seen that some eigen modes are not present, since they are not visible on the spectra. The modal excitation in case of coupled modes is indeed strongly influenced by the initial conditions [12]. It is known that the damping affects the proximity of each of these coupled eigen modes. In the present study where the damping is low, the coupled eigen modes are close to each other in terms of frequencies. This leads to the dominance of some coupled eigen modes on others depending on the excitation location case. An illustrative example is given in the following lines. On the one hand, the coupled torsion eigen mode at $f_{T 2}=625 \mathrm{~Hz}$ is observed in the spectra obtained with excitation at location SP2 (see FIGURE 22), whereas the eigen mode at $f_{T 3}=647 \mathrm{~Hz}$ does not appear at all. On the other hand, when the spark plug is located at the SP1 location, the eigen mode at $f_{T 2}=625 \mathrm{~Hz}$ is not visible because the one at $f_{T 3}=647 \mathrm{~Hz}$ has taken the advantage (see FIGURE 20).

The bending force impulse response time history experienced by the weakened guide vanes is shown in FIGURE 23. Since the impulse excitation is made at SP2 location, the bending force experienced by the furthest guide vane ( $\mathrm{gvB}$ ) from the spark plug has a lowest amplitude than the two others.

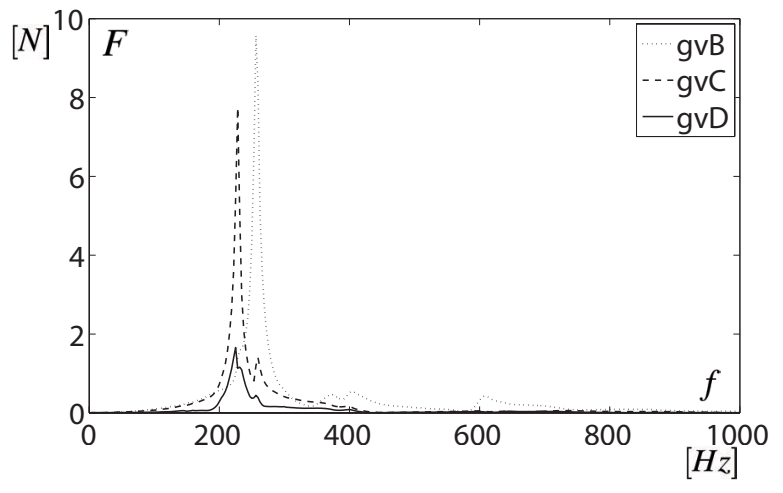

FIGURE 19. SPECTRA OF THE THREE GUIDE VANES (gvB, gvC and gvD) BENDING FORCE IMPULSE RESPONSE IN STILL WATER (EXCITATION IN SP1)

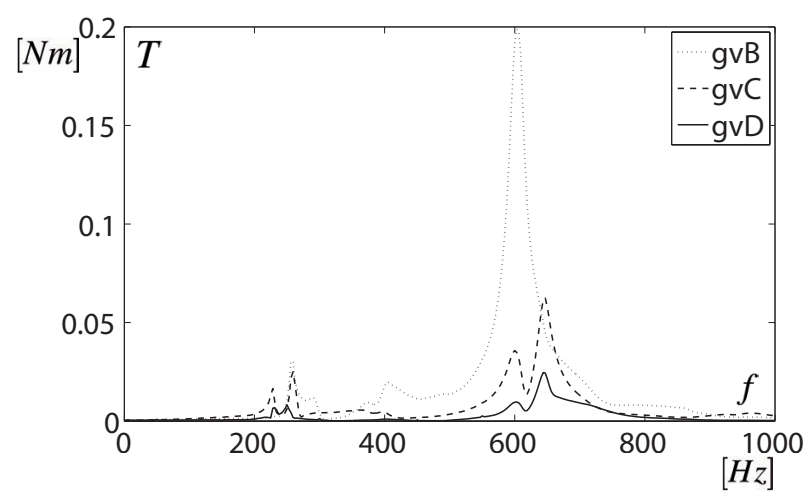

FIGURE 20. SPECTRA OF THE THREE GUIDE VANES ( $g v B$, gvC and gvD) TORSION TORQUE IMPULSE RESPONSE IN STILL WATER (EXCITATION IN SP1)

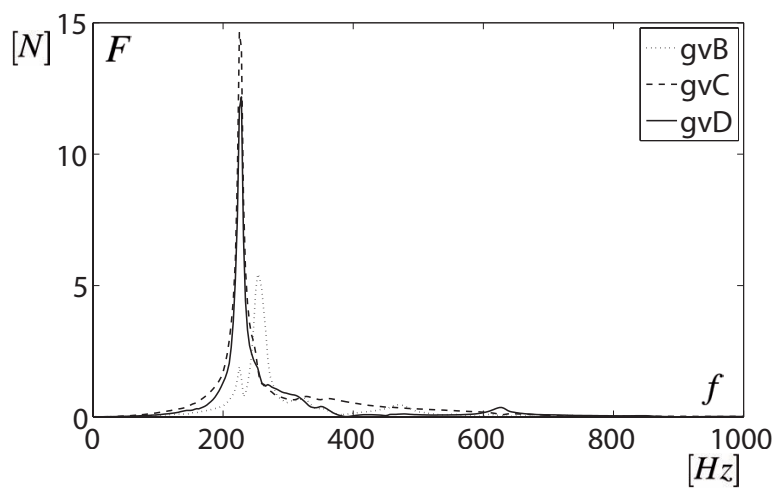

FIGURE 21. SPECTRA OF THE THREE GUIDE VANES ( $g v B$, gvC and gvD) BENDING FORCE IMPULSE RESPONSE IN STILL WATER (EXCITATION IN SP2) 


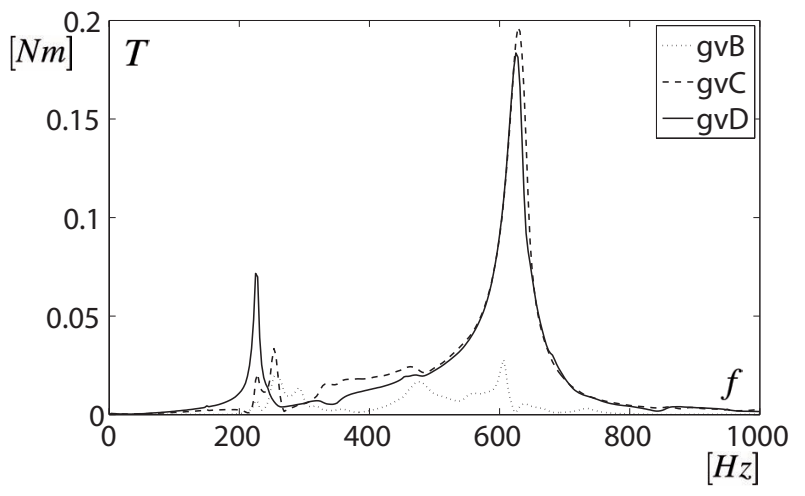

FIGURE 22. SPECTRA OF THE THREE GUIDE VANES (gvB, gvC and gvD) TORSION TORQUE IMPULSE RESPONSE IN STILL WATER (EXCITATION IN SP2)

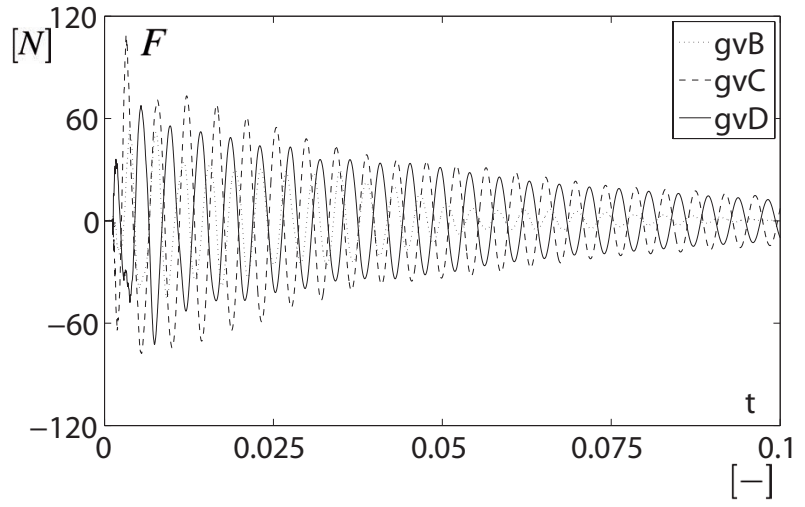

FIGURE 23. BENDING FORCE IMPULSE RESPONSE TIME HISTORY EXPERIENCED BY THE THREE GUIDE VANES (gvB, gvC and gvD) (EXCITATION IN SP2)

\section{Forced response with Rotor Stator Interaction (RSI) ex- citation}

Two operating points are investigated: OP\#1 and OP\#2. For these experimental acquisitions, a sampling rate of $51.2 \mathrm{kHz}$ digitizes the signals over $20.48 \mathrm{~s}$. A frequency resolution of about $0.049 \mathrm{~Hz}$ is thus recovered. The duration of the measure does not necessitate any spectral averaging over more than one acquisition. Although they are characterized by similar discharge $\phi$ and energy $\psi$ coefficients, the impeller blade passage frequency $f_{p}$ is not the same (see TABLE 6).

By adjusting the rotation speed between OP\#1 and OP\#2, the impeller blade passage frequency $f_{p}$ is modified and guide vane resonance cases can be reached. In OP\#2, the bending eigen mode at $225 \mathrm{~Hz}$ is caught by the first RSI harmonic leading to higher guide vane vibration amplitudes (see FIGURE 24).
TABLE 6. OPERATING POINTS SPECIFICATIONS

\begin{tabular}{ccc}
\hline & OP\#1 & OP\#2 \\
\hline$\phi[-]$ & 0.361 & 0.361 \\
$\psi[-]$ & 5.429 & 5.429 \\
$f_{p}[H z]$ & 147.0 & 112.5 \\
\hline
\end{tabular}

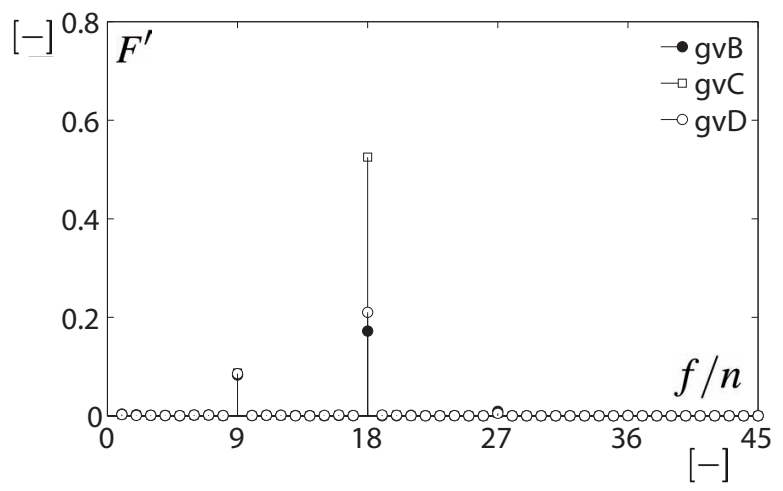

FIGURE 24. GUIDE VANES (gvB, gvC and gvD) BENDING FORCE SPECTRA AT RESONANCE (OP\#2)

On the contrary, the OP\#1 does not catch any eigen modes (see FIGURE 25). The guide vane $\mathrm{C}$ responds at a higher amplitude than the two others, mainly due to lower damping value. The guide vane $\mathrm{C}$ displacement phase average is obtained with the help of the laser-Doppler vibrometer and is represented in FIGURE 26. The measuring point is located at the leading edge (see FIGURE 15). The guide vane $\mathrm{C}$ experiences much higher amplitude in the operating point OP\#2 than in OP\#1 and the first harmonic clearly dominates the signal in the former case. The fluid pressure is locally influenced by the guide vane vibrations. In FIGURES 27 and 28, the fluctuating pressure coefficient spectra are given for different points in the vaneless gap close to guide vanes $\mathrm{C} \& \mathrm{D}$ (see FIGURE 15). At resonance, on the one hand, in the proximity of vibrating structures with low amplitude, that is close to guide vane D (sensors 95 and 69), the fundamental RSI frequency predominates in pressure signals. On the other hand, close to guide vane $\mathrm{C}$, a higher structural vibrations amplitude influences locally the fluid pressure. So, the $1^{\text {st }}$ harmonic of impeller blade passage frequency is dominant compared to the fundamental frequency. 


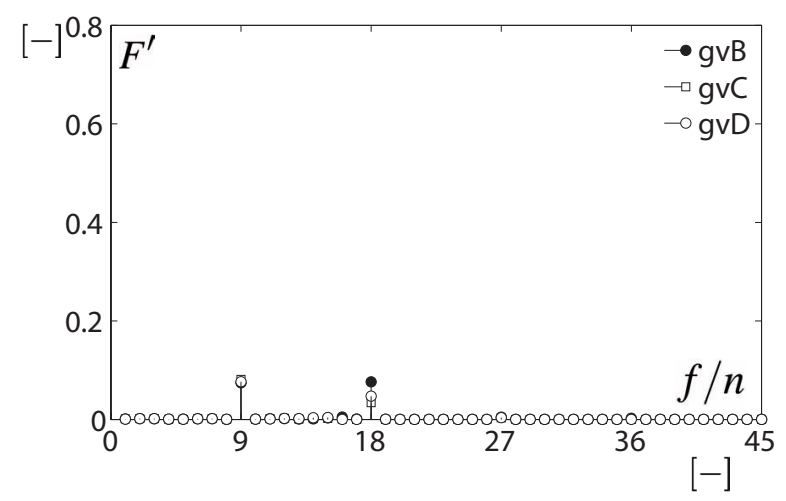

FIGURE 25. GUIDE VANES (gvB, gvC and gvD) BENDING FORCE SPECTRA OUT OF RESONANCE (OP\#1)

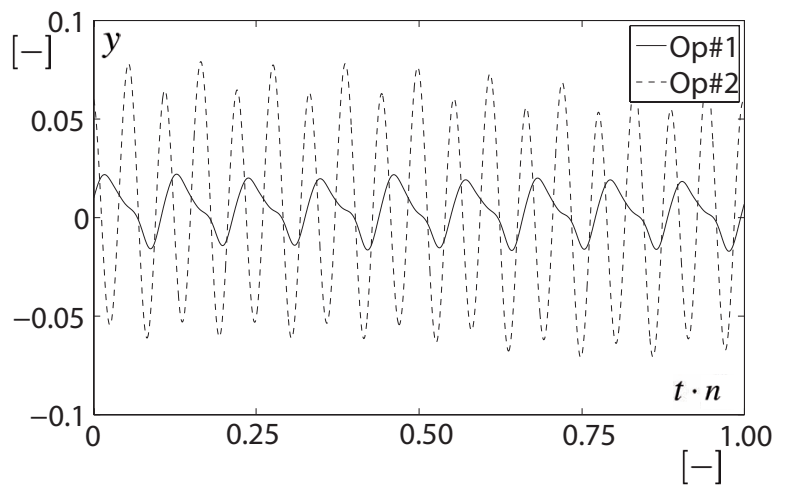

FIGURE 26. GUIDE VANE C DISPLACEMENT FOR THE TWO OPERATING POINTS

\section{CONCLUSION}

The present investigation is about fluid-structure coupling in the guide vanes of a pump-turbine scale model placed in the EPFL PF3 test rig. The use of an advanced instrument set provides interesting, complete and reliable fluid-structure coupling results. Relative fluctuating bending and torsion motion of three guide vanes are measured with the help of semi-conductor strain gages Wheatstone bridges. These especially weakened guide vanes are statically calibrated in terms of torsion torque and bending force. A laser-Doppler vibrometer is used to measure vibrating guide vane velocity. The vibrometer laser beam access to the concerned guide vane is made possible with the help of a Plexiglas window and Plexiglas stay vanes. Piezo-resistive pressure sensors are installed around the weakened guide vanes to monitor the influence of the structural vibrations on the surrounding flow. Finally, a non-intrusive impulse excitation system consisting of an immersed spark plug provides sufficient energy to the guide vanes to handle fluid-structure coupling in a reliable

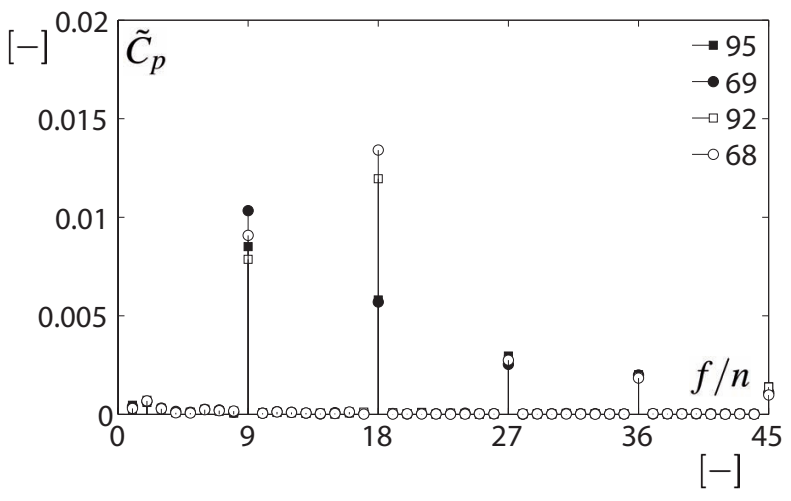

FIGURE 27. PRESSURE COEFFICIENT AT RESONANCE (OP\#2)

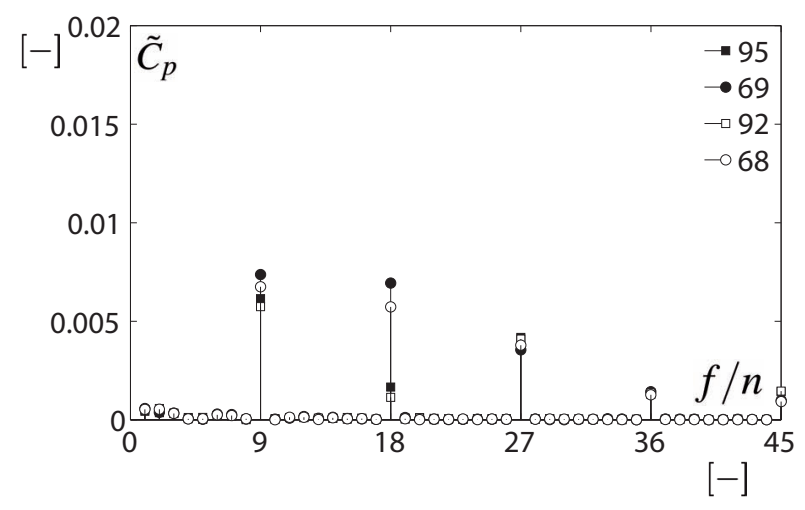

FIGURE 28. PRESSURE COEFFICIENT OUT OF RESONANCE (OP\#1

way. The results exhibit a strong coupling between the vibrating guide vanes and the unsteady flow. The impulse response system should be able to be used when operating the machine and could be a possible future outlook. A model of the three guide vanes cascade could also be developed in order to quantify the interaction degree between the blades. Finally, in a more industrial perspective, the transposition from the scale model results to prototype should be investigated.

\section{ACKNOWLEDGMENT}

The present investigation was carried out in the frame of HYDRODYNA II project (Eureka $N^{\circ} 4150$ ), in a partnership with ALSTOM Hydro, ANDRITZ Hydro, VOITH Hydro and UPCCDIF. The authors would like to thank the Swiss Federal Commission for the Technology and Innovation (CTI) and Swisselectric Research for their financial support as well the HYDRODYNA II partners for their involvement and support. 


\section{REFERENCES}

[1] Bouschon, M., Roulet, D., Miscioscia, T. and Pépin, P., 2008, Recent achievements in hydro actuators Hydro 2008 Proceedings Ljubljana, Slovenia.

[2] Yan, Y.J., Cui, P.L., Hao, H.N., 2008, Vibration mechanism of a mistuned bladed-disk. Journal of sound and vibration 317. pp. 294-307. 2008.

[3] Miyakozawa, T., Kielb, R.E., Hall, K.C., 2009, The effects of aerodynamic asymmetric perturbations on forced response of bladed disks. Journal of Turbomachinery, ASME.

[4] Brennen, C.E., 1982, A review of added mass and fluid inertial forces. Report CR 82.010. Naval Civil Engineering Laboratory. Port Hueneme, California.

[5] Chaplin, J.R., 2000, Hydrodynamic damping of a cylinder at $\beta=10^{6}$. Journal of Fluids and Structures. pp. 1101-1117

[6] Kaminer, A.A. and Kavitskii, B.M, 1976, Experimental investigation of hydrodynamic damping during bending oscillations of blade profiles in water flow. Strength of Materials. pp. 25-27.

[7] Theodorsen, Th., 1935, General Theory of Aerodynamic Instabiliity and the Mechanism of Flutter. NACA Report 496.

[8] Zobeiri, A., 2009, Investigations of Time Dependent Flow Phenomena in a Turbine and a Pump-Turbine of Francis Type: Rotor-Stator Interactions and Precessing Vortex Rope. Thesis N 4272. Ecole Polytechnique Fédérale de Lausanne.

[9] Del Pedro, M., Gmür Th., 2001, Eléments de mécanique des structures. Presses Polytechniques et Universitaires Romandes. Lausanne, Switzerland.

[10] Roth, S., Calmon, M., Farhat, M., Muench, C., Huebner, B. and Avellan, F., 2006, Hydrodynamic Damping Identification from an Impulse Response of a Vibrating Blade. Proceedings of the $3^{\text {rd }}$ IAHR International Meeting of the Workgroup on Cavitatio and Dynamic Problems in Hydraulic Machinery and Systems. Vol.1, pp. 253-270. Brno, Czech Republic.

[11] Pereira, F., Farhat, M., Avellan, F., 1993, Dynamic calibration of transient sensors by spark generated cavity. Proceedings of IUTAM Symposium on Bubble Dynamics and Interface Phenomena.

[12] Del Pedro, M., Pahud, P., 2003, Mécanique vibratoire, Systèmes discrets linéaires. Presses Polytechniques et Universitaires Romandes. Lausanne, Switzerland. 